\title{
Bovine chromosomal regions affecting rheological traits in rennet-induced skim milk gels
}

\author{
V. R. Gregersen, ${ }^{* 1,2}$ F. Gustavsson, $\dagger^{1} M$. Glantz, $†$ O. F. Christensen, ${ }^{*}$ H. Stålhammar, $\ddagger$ A. Andrén, $\S$ \\ H. Lindmark-Månsson,†\# N. A. Poulsen,II L. B. Larsen,II M. Paulsson, † and C. Bendixen* \\ *Department of Molecular Biology and Genetics, Faculty of Science and Technology, Aarhus University, Blichers Allé 20, PO Box 50, 8830 Tjele, \\ Denmark \\ †Department of Food Technology, Engineering and Nutrition, Lund University, PO Box 124, SE-221 00 Lund, Sweden \\ ¥VikingGenetics, PO Box 64, SE-532 21 Skara, Sweden \\ §Department of Food Science, BioCenter, Swedish University of Agricultural Sciences, Box 7051, SE-750 07 Uppsala, Sweden \\ \#Lantbrukarnas Riksförbund Dairy Sweden, Ideon Science Park, SE-223 70 Lund, Sweden \\ IIDepartment of Food Science, Faculty of Science and Technology, Aarhus University, Blichers allé 20, PO Box 50, 8830 Tjele, Denmark
}

\begin{abstract}
Optimizing cheese yield and quality is of central importance to cheese manufacturing. The yield is associated with the time it takes before the gel has an optimal consistency for further processing, and it is well known that gel formation differs between individual milk samples. By identifying genomic regions affecting traits related to rennet-induced gelation, the aim of this study was to identify potential candidate genes affecting these traits. Hence, rennet-induced gelation, including rennet coagulation time, gel strength, and yield stress, was measured in skim milk samples collected from 379 animals of the Swedish Red breed using low-amplitude oscillation measurements. All animals had genotypes for almost 621,000 segregating single nucleotide polymorphisms (SNP), identified using the Bovine HD SNPChip (Illumina Inc., San Diego, CA). The genome was scanned for associations, haplotypes based on SNP sets comprising highly associated SNP were inferred, and the effects of the 2 most common haplotypes within each region were analyzed using mixed models. Even though the number of animals was relatively small, a total of 21 regions were identified, with 4 regions showing association with more than one trait. A major quantitative trait locus for all traits was identified around the casein cluster explaining between 9.3 to $15.2 \%$ of the phenotypic variation of the different traits. In addition, 3 other possible candidate genes were identified; that is, UDP- $N$-acetyl- $\alpha$-D-galactosamine:polypeptide $N$ acetylgalactosaminyl-transferase 1 (GALNT1), playing a role in O-glycosylation of $\kappa$-casein, and 2 cathepsins, $C T S Z$ and $C T S C$, possibly involved in proteolysis of milk proteins. We have shown that other genes than the
\end{abstract}

Received March 14, 2014.

Accepted November 4, 2014.

${ }^{1}$ These 2 authors contributed equally to the work.

${ }^{2}$ Corresponding author: Vivi.Gregersen@agrsci.dk casein genes themselves may be involved in the regulation of gelation traits. However, additional analysis is needed to confirm these results. To our knowledge, this is the first study identifying quantitative trait loci affecting rennet-induced gelation of skim milk through a high-density genome-wide association study.

Key words: genome-wide association study, dairy cattle, milk gelation, casein

\section{INTRODUCTION}

In 2011 more than 18 million tonnes of cheese were produced in the world (International Dairy Federation, 2013). Both milk composition and other milk properties (e.g., SCC and $\mathrm{pH}$ ) have considerable effects on cheese yield and composition (Walstra et al., 2006), thus making it important to optimize the yield in cheese manufacturing. In rennet-induced gelation of milk, the CN $\left(\alpha_{\mathrm{S1}^{-}}, \alpha_{\mathrm{S} 2^{-}}, \beta-\right.$, and $\left.\kappa-\mathrm{CN}\right)$ in the form of micelles are of great importance. When rennet (chymosin) is added to milk, $\kappa-\mathrm{CN}$ is hydrolyzed, which leads to a destabilization of the micelles, and aggregates start to form (Walstra et al., 2006). Within cheese making, the aggregation time and the time it takes before the gel can be cut are important parameters. Rennet-induced gelation differs between milk samples from individual cows because of differences in, among others, the contents of total protein, $\mathrm{CN}$, calcium, and $\mathrm{pH}$ of milk (Frederiksen et al., 2011b; Gustavsson et al., 2014b). In addition, it has been observed that milk from some cows coagulates poorly (Ikonen et al., 1999; Gustavsson et al., 2014a); however, the reason for this is not fully understood. Frederiksen et al. (2011a) showed that gelation properties of well-coagulating milk were considerably impaired when adding noncoagulating as well as poorly coagulating milk when using milk from individual cows, showing the importance of optimizing cheese milk quality. 
As reviewed by Bittante et al. (2012), several studies have been conducted regarding the heritability of milk gelation properties. Heritability estimates of 0.21 to 0.38 have been reported for rennet coagulation time (RCT) and for gel strength $\left(\mathbf{G}^{\prime}\right) 0.12$ to 0.41 (Bittante et al., 2012). These results indicate that it could be possible to breed cows to obtain milk with better milk gelation properties. It is well known that different milk protein genetic variants affect both milk composition and milk gelation properties, as reviewed by Caroli et al. (2009) and Bittante et al. (2012). Documented effect on milk gelation properties has been found on genetic variants of $\kappa$ - and $\beta-\mathrm{CN}$ and of $\beta-\mathrm{LG}$ (Ikonen et al., 1999; Poulsen et al., 2013). However, conflicting results are found between studies. Some studies also reported effects of genetic variants of $\alpha_{\mathrm{S}^{-}} \mathrm{CN}$ on milk gelation properties (e.g., Lodes et al., 1996; Poulsen et al., 2013). The different $\mathrm{CN}$ do not only differ from each other regarding genetic variants, but also through different degree of phosphorylation and, in case of $\mathrm{k}-\mathrm{CN}$, also glycosylation (Farrell et al., 2004). Both phosphorylation (Frederiksen et al., 2011a; Jensen et al., 2012) and glycosylation of CN (Robitaille et al., 1993; Jensen et al., 2012; Bonfatti et al., 2014) have been shown to affect rennet-induced gelation properties.

Most studies conducted to investigate the effects of the bovine genome on milk composition and milk gelation properties rely on variations in the genetic variants of major milk proteins (Caroli et al., 2009; Bittante et al., 2012). However, it is difficult to assign effects to a certain variant, because the casein genes are tightly linked. In recent years, the genetic effect on milk composition has been analyzed using full genome studies and genome-wide association studies (GWAS; e.g., Kolbehdari et al., 2009; Schopen et al., 2011). Such studies provide substantial information on the chromosomal regions affecting specific milk traits and can be used to generate new hypotheses of genes underlying these traits. Schopen et al. (2011) performed a GWAS to identify chromosomal regions affecting milk protein composition. In their study, a total of 31 genomic regions on 20 bovine autosomes were found showing significant association with milk protein composition, total protein content, or both. Only 3 chromosomal regions harbor the genes coding for the most abundant milk proteins, i.e., BTA 5 ( $\alpha$-LA), BTA 11 ( $\beta$-LG), and BTA 6 (CSN cluster); however, other genes are also involved in the formation of milk proteins. In addition, Schopen et al. (2011) showed that not all genetic variation regarding milk protein composition and total protein content could be explained by the earlier known genetic variants. Furthermore, noncoagulating milk has been analyzed to identify causal genes performing a genome scan using microsatellite markers (Tyrisevä et al., 2008). The aim of this study was to identify regions within the bovine genome affecting rennet-induced gelation. A GWAS was performed in 379 Swedish Red (SR) cows using markers from Illumina's Bovine HD SNPchip containing 777,000 SNP. Based on SNP highly associated with the traits, haplotypes across the SNP set regions were inferred and used for further analyses of the associated loci. The aim of the study was to identify genetic markers affecting rennet-induced gelation in general, which could be used within animal genomic breeding schemes to optimize cheese production.

\section{MATERIALS AND METHODS}

\section{Animals and Samples}

Morning milk samples and blood samples were collected from 395 SR cows in 20 different farms (April to May 2010 and September 2010 to April 2011) located in the same geographical region in the southern part of Sweden. Between 19 and 24 individual milk samples were collected from each herd, and each herd was sampled the same day. The 395 cows descended from 168 sires and 72 paternal grandsires. A total of 100 sires had only 1 daughter, 29 sires had 2 daughters, and the 2 largest families comprised 13 and 17 half-sibs, respectively. In total, 158 maternal grandsires fathered the mothers, among which 26 also fathered some of the cows. The majority of the cows were in lactation number 1 to 3 (1\% in lactation number 4$)$ and in lactation wk 7 to 40 (2\% before lactation wk 7 and $10 \%$ after lactation wk 40). All cows were milked 2 times (in total 287 of the sampled cows from 15 of the herds) or 3 times (in total 108 of the sampled cows from 5 of the herds) per day. Separate milkings were performed on all cows, and the individual milk samples were thoroughly mixed before an aliquot was sampled, cooled, and transported to Lund University, Sweden, arriving at the day of sampling, whereas another aliquot of each sample was cooled and transported to Aarhus University, Foulum, Denmark, arriving the day after sampling. Fresh milk samples were analyzed for contents of total protein, $\mathrm{CN}$, fat, and lactose by an infrared technique (MilkoScan FT2, Foss Electric, Hillerød, Denmark). This method has previously been validated for CN measurements (Sørensen et al., 2003). Somatic cell count was measured by using flow cytometry (CombiFoss 5000, Foss, Hillerød, Denmark) at a certified dairy analysis laboratory (Eurofins Steins Laboratory, Jönköping, Sweden). When collecting the milk samples, milk yield on the day of sampling was recorded. The $\mathrm{pH}$ of the milk samples was measured at $10^{\circ} \mathrm{C}$ the day after sample collection. Of the 395 milk samples, 379 milk samples, corresponding to $96 \%$, had SCC below 300,000 
cells $/ \mathrm{mL}$ and were included in the rheological study, whereas all blood samples $(\mathrm{n}=395)$ were genotyped and used for creating phased haplotypes.

\section{Rheological Analyses}

At the day of sampling, the collected milk samples were defatted by centrifugation at 2,000 $\times g$ for 30 $\min$ at $4^{\circ} \mathrm{C}$ with subsequent removal of the fat layer. For preservation purposes, bronopol (Sigma-Aldrich Logistik Gmbh, Schnelldorf, Germany) was added. A bronopol solution of $17 \%$ (wt/vol) was added to all milk samples $(2 \mu \mathrm{L} / \mathrm{mL})$, all according to Hallén et al. (2007), and the samples were stored at $6^{\circ} \mathrm{C}$ until measurements were performed ( 1 to $4 \mathrm{~d}$ after sampling). Gel strength $\left(\mathrm{G}^{\prime}\right)$, RCT, and yield stress (YS) were determined after inducing rennet gelation on all skim milk samples using low-amplitude oscillation measurements (Stresstech rheometer, ReoLogica Instruments AB, Lund, Sweden) according to the method of Glantz et al. (2011). After preheating the milk sample to $32^{\circ} \mathrm{C}$ for $30 \mathrm{~min}$ in a water bath, gelation was induced by adding chymosin (Chy-Max Plus, 205 international milk clotting units/mL, Chr. Hansen A/S, Hørsholm, Denmark) to a final concentration of 0.09 international milk clotting units $/ \mathrm{mL}$ of milk. Gel strength $30 \mathrm{~min}$ after chymosin addition defined $\mathrm{G}^{\prime}{ }_{30}$, and $\mathrm{G}_{\text {max }}^{\prime}$ was defined as the maximum recorded gel strength in the full run $(40 \mathrm{~min})$, where $\mathrm{G}^{\prime}=\sigma_{0} / \gamma_{0} \cdot \cos \delta\left(\sigma_{0}=\right.$ maximum stress; $\gamma_{0}=$ maximum shear strain; $\delta=$ phase angle, or phase difference between the strain and stress). Rennet coagulation time was defined as the point of time when a continuous increase in $\mathrm{G}^{\prime}$ was detected by the instrument. Forty minutes after chymosin addition, a stress sweep was conducted where the shear stress was increased in 100 intervals from 0.1 to $300 \mathrm{~Pa}$. Yield stress was defined as the shear stress at the point where the viscosity reached $90 \%$ of the maximum recorded viscosity. Because the YS is a measurement of gel breakdown, samples that had not coagulated after 40 min (65 samples $\sim 18 \%$ ) were not included in this trait.

\section{Genotyping and Data Validation}

Genomic DNA was isolated from blood samples of all specimens by treatment with proteinase $\mathrm{K}$ followed by sodium chloride precipitation. For all cows SNP genotyping was performed by GenoSkan A/S, Denmark, using the BovineHD BeadChip (Illumina, San Diego, $\mathrm{CA}$ ), according to the protocol provided by the manufacturer. Single nucleotide polymorphism calling using the genotyping module of the GenomeStudio software version 2010.2 (Illumina) was performed by GenoSkan A/S, Denmark. They manually assessed all SNP with a call frequency below 0.95 and low heterozygosity $(<5 \%)$ for clustering problems and adjusted the clusters if possible. Thereafter, samples with call rates below 0.95 as well as SNP with a call frequency below 0.95 were excluded. The data were further analyzed by the Haploview 4.2 software (Barrett et al., 2005) to account for low minor allele frequency $(<0.02)$ and deviation from Hardy-Weinberg proportions $(P<0.001$; Wigginton et al., 2005). The SNP were ordered according to the position given by the manufacturer (Bos taurus UMD3.1; Zimin et al., 2009), and tag SNP were identified using Haploview 4.2's implementation of the pairwise Tagger algorithm using an $\mathrm{r}$ limit of 0.8 and an logarithm of odds threshold of 3 (de Bakker et al., 2006). The tag SNP represent the number of independent tests that have been conducted, and these were used to generate a less conservative $5 \%$ Bonferroni corrected significance level for the association and haplotype analyses. The corrections for multiple testing were performed both genome wide and chromosome wide using the formula $\alpha / n$, where $\alpha=0.05$ was the desired significance level and $n$ was the number of independent tests. The final number of SNP used in the analysis was 620,979 . The genome-wide Bonferroni significance level was set to $2.28 \times 10^{-7}$ based on the number of SNP represented by the tag SNP $(219,218)$. Chromosome-wide levels were in the range between $1.14 \times 10^{-5}$ and $4.0 \times 10^{-6}$ depending on the number of tag SNP mapped to a given chromosome (between 4,372 and 12,216).

\section{Population Stratification}

To assess whether the sample population suffered from structural stratifications, a principal components analysis was performed using the genomic predicted kinship already estimated (Gustavsson et al., 2014c). The principal components analysis was performed using the prcomp package of R (Holland, 2008).

\section{The 2-Step Procedure}

The association analysis performed in this study is different from other studies. In the first step, an initial simple GWAS scan, not taking into account the nongenetic factors, was performed to identify regions of potential interest. Because this analysis potentially could lead to identification of false positives, a second step, which is an analysis of the highly associated SNP sets, was performed using the full model. The SNP sets are defined as SNP on the same chromosome with a maximum distance of $10 \mathrm{Mb}$ between neighboring SNP, and they should be associated to the trait at least at the smallest $5 \%$ chromosome-wide significance level used within the study $\left(P<1.1 \times 10^{-5}\right)$. In addition, to 
qualify for being selected as a SNP set, at least 2 SNP should be present and at least 1 should be significant at the $5 \%$ chromosome-wide level. The SNP within the SNP sets are then ordered and phased as later described and analyzed by a mixed model for an additive genetic effect in the second step.

A clear benefit of this procedure is the possibility to assess the SNP in combination instead of as single SNP. Whole-genome sequencing, based on few animals representing the different haplotypes (phases) derived from SNP sets, can be used to identify causal variations that represent SNP within the genome (data not published). In addition, if a haplotype is explained by SNP that are not included in the HD chip, the wholegenome sequencing approach assists in the downstream identification of these SNP, where possible SNP patterns representing only the haplotype will be explored in the region of interest. Hence, this approach is very valuable when looking for causative variations of low frequencies.

\section{Genome-Wide Association Study}

A GWAS was performed as a simple scan to identify SNP highly associated with the rheological traits identified from the rheological analyses; that is, RCT, YS, $\mathrm{G}_{30}^{\prime}$, and $\mathrm{G}_{\text {max }}^{\prime}$. The traits were log-transformed to fit the Gaussian distribution. The analysis was performed using the "-at" option of analyzing the total evidence of association conducted as a simple $F$-statistic implemented within the QTDT program package (version 2.5.1; QTDT, 2005). Even though the program package used was developed mostly for transmission disequilibrium test, the chosen model evaluates the total evidence for association and is not a transmission disequilibrium test. It can, however, produce misleading results in the presence of population stratification (QTDT, 2008). Fortunately, the only structure found in the sampled population was produced by the half-sib families (Supplemental Figure S1; http://dx.doi.org/10.3168/ jds.2014-8136), and these were accounted for by the model. In addition, this model evaluates all available data in contrast to the true transmission disequilibrium test that is dependent on parental genotypes being heterozygote to be informative. The GWAS scan for identification of potentially interesting genomic regions was conducted using information of all animals as a 2-generation pedigree; however, the nongenetic factors potentially affecting the traits were not included in this statistical model. Even though this analysis could potentially produce false negatives, an in-house investigation of a similar data set has not identified this to be a problem (data not shown). Note that such nongenetic factors are accounted for in the subsequent analysis of the QTL regions that is presented below.

\section{Phasing Algorithm}

Because SNP sets are selected based on strong association to a given trait as previously described, we here define haplotypes as phased patterns of highly associated SNP. Because of the reduced number of SNP within the SNP sets compared with the entire region, a relatively simple algorithm can be applied to infer the haplotypes, without significant loss of information. Haplotypes were inferred using the SNP sets by the recursive algorithm as described in Gregersen et al. (2012). Briefly, a binary tree is constructed with the height $=1+$ the number of SNP in the set (root + tree) by going through the genotype combinations of each animal. A left and right branch represents allele 1 and allele 2, respectively. The leaf nodes contain information on the phase and a counter that sums the probability of the specific phase within the population. In a second run the most likely phase is selected and the additional phase is calculated by subtracting the first phase from the genotypes.

\section{Mixed Models}

The following mixed model was used to assess the fixed effects of week of lactation and lactation number:

$$
Y_{i}=\mu+H_{\operatorname{herd}(i)}+w_{\operatorname{week}(i)}+l_{\text {lactation }(i)}+e_{i},
$$

where $Y_{i}$ is the trait value for individual $i, \mu$ is the intercept, $H_{\text {herd }(i)}$ is the random effect of herd and test day (20 farms), and $e_{i}$ is the random effect of the residual variance, for individual $i$. All random effects were assumed to be normally distributed with independence covariance structure. In addition, fixed effects of $w_{\text {week }(i)}$ and $l_{\text {lactation(i) }}$, the every-other-month week of lactation (4 intervals) and lactation number (1 or more), respectively, were included in the model. The tests were performed by removing either "week of lactation" or "lactation number" in the null model and then estimating the fixed effects of the variables. In addition, $\mathrm{pH}$ and SCC were assessed by introducing them into the model as class effects one at a time.

The most common haplotype within a given SNP set was identified, and an analysis of the effect of this haplotype (versus all other haplotypes) was analyzed to estimate the additive effect and the phenotypic variance explained by the haplotype. Animals with missing genotypes were placed within the "all other haplotypes" category. The lme4 package of R (Bates et al., 2008) 
was used for the purpose. The additive haplotype effects were estimated, for each SNP set at a time, using the following mixed model:

$$
Y_{i}=\mu+H_{\mathrm{herd}(i)}+w_{\operatorname{week}(i)}+l_{\text {lactation }(i)}+\beta h(i)+e_{i},
$$

where $Y_{i}, \mu, H_{\text {herd }(i)}, e_{i}, w_{\text {week }(i)}$, and $l_{\text {lactation }(i)}$ were as described above. The haplotype effect was a regression on $h(i)$, where $h(i)=1$ if there were 2 copies of the most common haplotype, 0 if there was one copy, and -1 if there were zero copies, and the parameter $\beta$ was the additive genetic effect of the most common haplotype. A significance test for $\beta=0$, i.e., no haplotype effect, was performed. If the most common haplotype did not show any significance, the second-most-common haplotype was evaluated as well. Furthermore, if the mean value of the trait for a given haplotype was found to be extreme compared with the rest of the haplotypes, this haplotype was evaluated by the model contrasting all other haplotypes as explained above.

The phenotypic variance explained by the tested haplotype was estimated using the output from the ANOVA statistics. The total variance was computed as the sum of the herd, residual, and haplotype variance for the model, where the variance of the haplotype effect $\left(\operatorname{Var}_{\text {hap1 }}\right)$ was estimated as

$$
\operatorname{Var}_{\text {hap } 1}=2 \times \text { freqhap1 } \times(1-\text { freqhap1 }) \times\left(\text { effect }_{\text {hap } 1}\right)^{2} .
$$

Here freqhap1 and effect $t_{\text {hap } 1}$ were the frequency and the estimated additive genetic effect of haplotype 1, respectively. The variance of the haplotype effect was then divided by the total variance and multiplied by 100 to get the value in percentage.

The $P$-values obtained from the mixed-model analysis were adjusted for multiple testing by the Bonferroni correction as described above. We decided to use the same adjustment as for the simple GWAS because we used the SNP for identifying haplotypes. In addition, this strict level of correction should decrease the likelihood of selecting false positives as true regions.

\section{RESULTS}

\section{Milk Composition and Rheology Measurements}

In Table 1 the mean values of fat, lactose, $\mathrm{CN}$, and total protein contents of the milk samples are presented and are shown to be $4.1,4.7,2.7$, and $3.6 \%$, respectively. The average milk composition in the individual milk samples included in this study agrees well with the national milk recording and with studies on individual milk samples from SR cows reported earlier. According to the national milk recording the average fat and total protein contents in SR milk were 4.4 and 3.6\%, respectively, at the year of sampling (Swedish Dairy Association, 2011). Fat, lactose, CN, and total protein contents were in the ranges of previously reported data on individual SR cows (Wedholm et al., 2006a; Glantz et al., 2012). Using the Stresstech rheometer, 4 rennetinduced gelation traits were determined in skim milk: $\mathrm{RCT}, \mathrm{G}_{30}^{\prime}, \mathrm{G}_{\max }^{\prime}$, and YS, and these are also presented in Table 1.

\section{Fixed Effects}

In relation to the mixed model, the variables "week of lactation" and "lactation number" were found to affect all traits significantly with $P$-values ranging from 4.84 $\times 10^{-6}$ to 0.04 , and in addition, $\mathrm{pH}$ was found to have a fixed effect on $\operatorname{RCT}\left(P=5.28 \times 10^{-5}\right)$. No effects were found for SCC.

\section{Identification of QTL Regions}

In the preliminary GWAS scan, a total of 46 suggestive SNP set regions were identified (Table 2, Supplemental Table S1; http://dx.doi.org/10.3168/ jds.2014-8136). These regions were further analyzed by the haplotype approach using the mixed models, and 21 of the regions were identified to have an additive effect of the analyzed haplotype for the given trait after adjusting for multiple testing (Table 2). For all of these SNP set regions, estimated additive effects of the haplotype were substantial. For RCT, the additive effects of having a copy of the haplotype ranged between 0.09 and 0.30 for the significant SNP set regions, however, not always as a beneficial effect as seen from the sign of the value (Table 2). A negative effect of the haplotype in this case, however, indicates a better coagulation time due to a decrease in RCT, and this was identified in 7 out of the 10 significant cases. The frequency of the significant haplotypes varies quite a lot, indicating different potential in relation to selection. For instance in relation to the undesirable haplotype on BTA 18 , the effect of the haplotype is large, but it is only represented with a low frequency in the population. Therefore, the gain of selection toward this haplotype might be small compared with other haplotypes of smaller effect but with a lower frequency and hence a better selection potential, e.g., haplotype 1 on BTA 15b. For the 2 traits measuring the strength of the gel, $\mathrm{G}_{30}^{\prime}$ and $\mathrm{G}_{\max }^{\prime}$, the estimated effects ranged between 0.27 and 0.43 , and 0.34 and 0.35 , respectively (Table 2 ). Of the 7 significant haplotypes affecting $\mathrm{G}^{\prime}{ }_{30}$, all had a favorable effect on the trait except in one case where a decrease in the $\mathrm{G}_{30}^{\prime}$ value was identified. Because the frequency of this particular haplotype was low, it could be potentially 
Table 1. Descriptive statistics of milk traits and rheological properties of rennet-induced skim milk gels of the analyzed Swedish Red cows ${ }^{1}$

\begin{tabular}{|c|c|c|c|c|c|}
\hline Trait & $\mathrm{n}$ & Mean & $\mathrm{SD}$ & Minimum & Maximum \\
\hline Fat $(\%)$ & 379 & 4.1 & 0.9 & 1.3 & 8.6 \\
\hline Protein (\%) & 379 & 3.6 & 0.4 & 2.9 & 4.8 \\
\hline $\mathrm{CN}(\%)$ & 358 & 2.7 & 0.1 & 2.3 & 3.1 \\
\hline Lactose (\%) & 358 & 4.7 & 0.1 & 4.2 & 5.0 \\
\hline $\mathrm{pH}^{2}$ & 379 & 6.8 & 0.1 & 5.6 & 7.0 \\
\hline Week of lactation & 379 & 26.0 & 11.0 & 3.0 & 61.0 \\
\hline Yield $\mathrm{DS}^{3}(\mathrm{~kg})$ & 311 & 30.0 & 9.9 & 6.0 & 62.0 \\
\hline $\operatorname{SCC} \mathrm{DS}(\times 1,000 / \mathrm{mL})$ & 379 & 47.0 & 46.0 & 2.0 & 278.0 \\
\hline $\mathrm{RCT}^{4}(\min )$ & 379 & $19.0(1.19)$ & $12.0(0.27)$ & $2.7(0.4)$ & $>40(>1.6)$ \\
\hline $\mathrm{G}_{30}^{\prime}{ }^{5}(\mathrm{~Pa})$ & 379 & $45.1(1.23)$ & $51.5(0.76)$ & $0(0)$ & $276.1(2.4)$ \\
\hline $\mathrm{G}_{\text {max }}^{\prime}{ }^{\prime}(\mathrm{Pa})$ & 379 & $64.8(1.33)$ & $65.8(0.82)$ & $0(0)$ & $312.7(2.5)$ \\
\hline $\mathrm{YS}^{7}(\mathrm{~Pa})$ & 315 & $15.5(1.19)$ & $5.9(0.17)$ & $2.8(0.6)$ & $33.4(1.5)$ \\
\hline
\end{tabular}

${ }^{1}$ Values within parentheses for the rheological properties are used in the genetic analyses.

${ }^{2}$ Measured on raw and unskim milk at $10^{\circ} \mathrm{C}$.

${ }^{3} \mathrm{DS}=$ day of sampling.

${ }^{4} \mathrm{RCT}=$ rennet coagulation time; values within parentheses shows $\log _{10}(\mathrm{RCT})$.

${ }^{5} \mathrm{G}_{30}^{\prime}=$ gel strength after 30 min of gelation; values within parentheses shows $\log _{10}\left(\mathrm{G}_{30}^{\prime}+1\right)$.

${ }^{6} \mathrm{G}_{\text {max }}^{\prime}=$ maximum gel strength; values within parentheses shows $\log _{10}\left(\mathrm{G}_{\max }^{\prime}+1\right)$.

${ }^{7} \mathrm{YS}=$ yield stress excluding noncoagulating samples (defined as $\mathrm{YS}=0$ ); values within parentheses shows $\log _{10}(\mathrm{YS})$.

interesting in breeding. Two SNP set regions affecting $\mathrm{G}_{\text {max }}$ were significant after adjustment for multiple testing. The significant haplotype had a negative effect on the trait in one case and a positive effect on the trait in the other. However, the frequencies of the respective haplotypes indicate almost equal contribution if used for selection. For YS, 2 SNP set regions were identified to affect the trait, and the effects of the most common haplotype were estimated to be -0.09 and 0.05 , respectively, with the haplotype representing BTA 6 being the most beneficial in relation to selection (Table 2).

The phenotypic variance explained by a single SNP set region in this study was estimated to range between 4.3 and $15.2 \%$, indicating that some SNP set regions have a greater effect on the trait than others. The region on BTA 6 that overlapped between all traits explained a large proportion of the phenotypic variance for all traits. In addition, the regions on BTA 13, 15a, and 29 (Table 2) were identified for more than one traits.

\section{DISCUSSION}

This study reports chromosomal regions affecting rennet-induced coagulation properties and possible candidate genes. This is the first time this approach has been performed for rennet-induced coagulation properties, thus adding new knowledge to the dairy and breeding research community. Even though the present study is based on a limited number of cows, the results generated will give an indication of which regions within the bovine genome that could be interesting for further analysis using a larger sample population.

\section{Identification of Regions Associated with the Traits}

In total, 46 suggestive SNP set regions were identified in relation to the 4 traits analyzed. Among the 46 suggestive SNP sets, a total of 21 SNP sets were significantly identified by a haplotype analysis using a mixed model with an additive effect of the haplotype, and in most cases the effect was found in relation to the most common haplotype. For the 21 significant SNP set regions, the estimated effects of the significant haplotype were substantial, explaining between 4.3 and $15.2 \%$ of the phenotypic variance. Because the $16 \%$ of the cows producing noncoagulating milk were kept in the data set for all traits except YS, the results might be compromised (Cecchinato et al., 2011). However, the right-censored linear Gaussian and survival model suggested by Cecchinato and Carnier (2011) was designed for patient data of censored records. In these cases, the percentage of censored data would be much higher and the need to cope with the large proportion would be necessary. In the present study, the relatively low proportion of noncoagulating samples compared with other censored data sets would probably not affect the results to a large degree. However, even though a histogram of the residuals from the model showed a slight asymmetry for the traits containing the noncoagulation samples, we do not believe that these affect the results considerably. Even though the estimates of both the fixed effect and variance explained of the most common haplotype might be overestimated, keeping the noncoagulating samples within the analysis should be seen as a trade-off. By keeping the noncoagulating samples 
Table 2. Suggestive QTL regions in the Swedish Red breed for rheological parameters in rennet-induced skim milk gels in addition to a haplotype analysis for an additive effect of the analyzed haplotype within the QTL

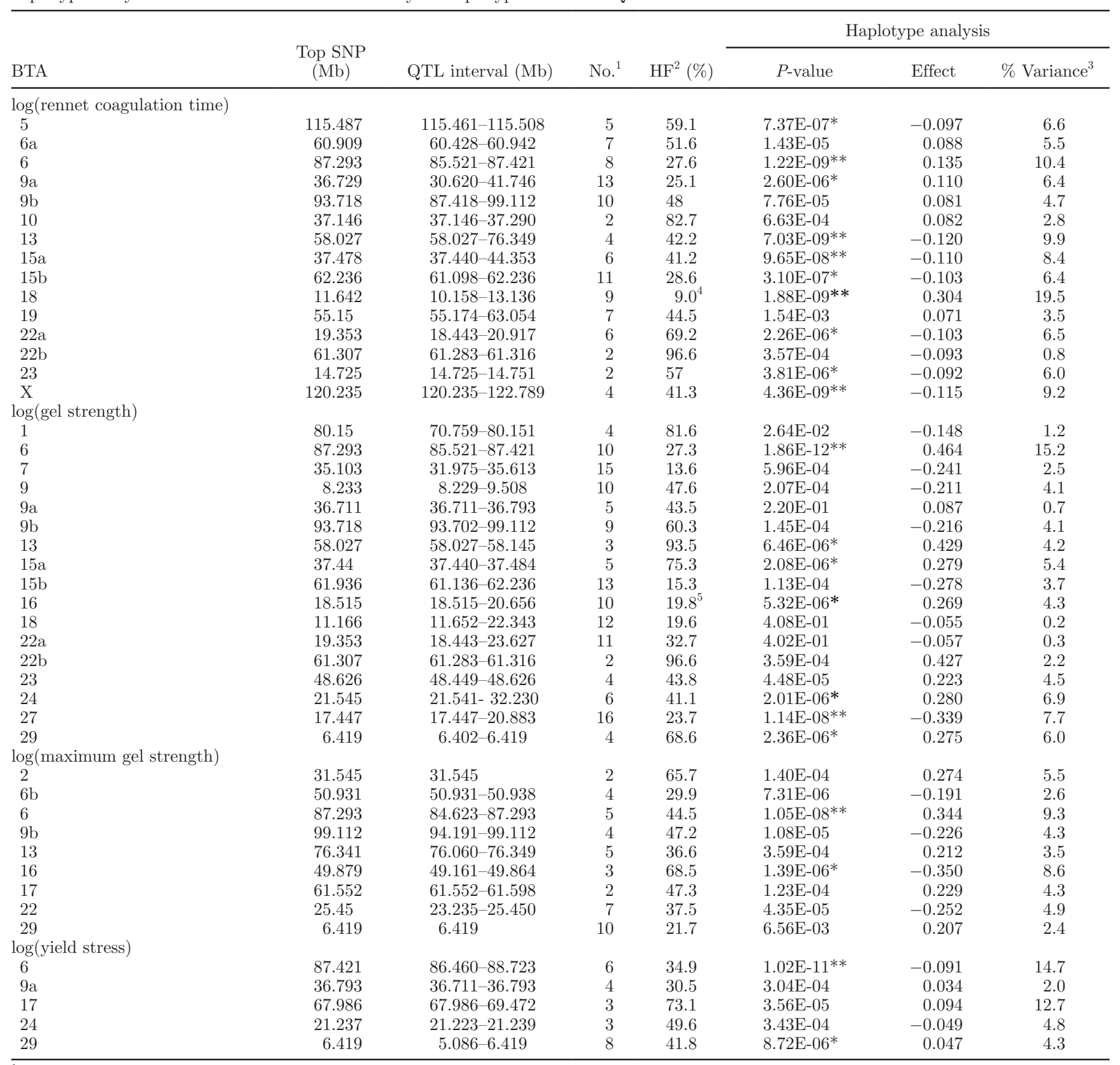

${ }^{1}$ No. $=$ number of identified haplotypes with a frequency above $1.5 \%$.

${ }^{2} \mathrm{HF}=$ haplotype frequency of the analyzed haplotype. If not otherwise indicated, the most frequent haplotype.

${ }^{3} \%$ Variance $=$ phenotypic variance explained by the haplotype.

${ }^{4}$ Analysis significant for the fifth-most-frequent haplotype.

${ }^{5}$ Analysis significant for the second-most-frequent haplotype.

*,**Significant at the $5 \%$ chromosome-wide and $5 \%$ genome-wide level, respectively.

in the data, the statistical power was greater and a ity of the rheological traits. In addition, because the greater number of associated regions were observed. heritability for these types of traits has been identiAltogether, this does, however, illustrate the complex- fied to be moderate to high (Bittante et al., 2012), the 
likelihood of finding haplotypes having an effect on the traits is reflected by the results. Besides, a comparison of heritability estimates for $\mathrm{G}^{\prime}$ performed by Bittante et al. (2012) show that by including the noncoagulating samples, the heritability estimates are higher than if they are not included. Furthermore, a previous study on the same sample set shows heritability estimates for $\mathrm{G}_{\text {max }}^{\prime}$ and YS to be 0.53 (SD 0.15) and 0.43 (SD 0.18), respectively (Gustavsson et al., 2014c), which partially could explain the large proportion of phenotypic variance explained by this analysis. Even though the sample set is limited, genomic relationships were used to estimate heritabilities in Gustavsson et al. (2014c). Therefore, the accuracy would be expected to be higher than by using pedigree relationships (Veerkamp et al., 2011).

The largest number of regions was identified in relation to RCT. Previously, milk $\mathrm{pH}$ has been found to be correlated with the coagulation time, with lower $\mathrm{pH}$ having a favorable effect on RCT, i.e., the coagulation time decreases with a decreasing $\mathrm{pH}$ (e.g., Zoon et al., 1989). This relation can also be seen in the present study, because $\mathrm{pH}$ is statistically significant when included as a fixed effect into the model. Therefore, at least some of these regions could potentially be regulating the $\mathrm{pH}$ balance in milk, leading to the difference in coagulation time.

The larger half-sib families included in the data sample were found to produce structure, but because the initial analysis accounted for this structure, we do not believe that it will affect the results produced by the subsequent analyses. Even though the mixed model included neither a sire effect nor an animal effect, the results obtained by the analysis were not believed to be compromised by this choice. The reason for this is that a study design with daughters ( $\mathrm{n}=$ $379)$ of many different sires $(\mathrm{n}=168)$ on the one hand makes it difficult to separate a sire effect or an animal effect from the residual error effect and on the other hand should minimize the possible biases due to polygenic effect. Furthermore, only minor differences were seen in relation to including the sire effect in the mixed model (Supplemental Table S2; http://dx.doi. org/10.3168/jds.2014-8136). However, the average level of the $P$-values was slightly higher when including the sire effect, which would result in a reduction of the number of marginally chromosome-wide significant regions for $\mathrm{RCT}$ and $\mathrm{G}_{30}$. It should be noticed that 2 of the regions in relation to $\mathrm{G}_{30}^{\prime}$ overlap with significant regions affecting RCT, suggesting that the Bonferroni correction might be too conservative because it is likely that both traits could be affected by the same gene. Inclusion of the animal effect failed because the model could not distinguish between the residual effect and the genetic component, leaving the model unable to converge.

\section{Confirmation of Associated Genomic Regions}

Some indications of overlap exist between the chromosomal regions found in a study by Tyrisevä et al. (2008) and by the present study. In one or more families, Tyrisevä et al. (2008) found significant loci affecting rennet-induced gelation on BTA 13, 15, and 16 around the maximum positions of markers BMS2319, JAB1, and IDVGA49, respectively. All these markers are situated less than $10 \mathrm{Mb}$ from SNP sets affecting RCT (BTA 13 and 15), $\mathrm{G}_{30}^{\prime}$ (BTA 15), and $\mathrm{G}^{\prime}{ }_{\max }$ (BTA 16) identified in the present study. Because Tyrisevä et al. (2008) used a trait describing extreme gelation properties and microsatellite markers in contrast to the full-genome marker set used in the present study, it is interesting to see overlap between the 2 studies. In addition, it shows that several of the associated regions might be related to noncoagulation of the milk.

Kolbehdari et al. (2009) found a significant SNP on BTA 13 for protein percentage that is positioned on $68,711 \mathrm{Mb}$, which lies within the region identified on BTA 13 in the present study. This region was found to have a genome-wide significant effect on RCT, and the significant haplotype explained about $9.9 \%$ of the phenotypic variance of the trait. Furthermore, Schopen et al. (2011) showed significant SNP on BTA 6 affecting the relative concentration of all milk proteins, including the whey proteins, together with protein content and $\mathrm{CN}$ index. This region was also identified to be genomewide significant in the present study, strengthening the effect of protein content and composition on rennetinduced gelation. Interestingly, the region on BTA 13 identified in the present study also overlaps the results obtained by Schopen et al. (2011). They found a single SNP to be significantly associated with the relative concentration of $\kappa-\mathrm{CN}$ on BTA 13 at $60,542 \mathrm{Mb}$. Because this SNP is located within the region identified on BTA 13 , the effect of the relative concentration of $\kappa-\mathrm{CN}$ on rennet-induced gelation could be strengthened. In addition, Gambra et al. (2013) identified 25 SNP associated with the absolute concentration of $\mathrm{k}-\mathrm{CN}$, and especially, one of the SNP could be of interest in relation to findings in the present study. The interesting SNP is located in the MTUS1 gene within the genome-wide significant region on BTA 27. The fixed effect of the significant haplotype has a large negative effect on $\mathrm{G}^{\prime}{ }_{30}$, and it was found to explain $7.7 \%$ of the phenotypic variation of the trait. The overlap between the study by Gambra et al. (2013) and the present study indicates that a gene affecting the concentration of $\kappa$ - $\mathrm{CN}$ might be responsible for the QTL within this location. 
However, studies have also identified other genes to affect rennet-induced gelation, which could not be confirmed in the present study. Glantz et al. (2011) studied the SR and Swedish Holstein breeds and found an effect of the leptin receptor gene $(L E P R)$ on BTA 3 on $\mathrm{G}^{\prime}$, $\mathrm{RCT}$, and cheese hardness as well as of the leptin gene $(L E P)$ on BTA 4 on $\mathrm{G}^{\prime}$. Furthermore, Cecchinato et al. (2012) identified the stearoyl-coenzyme A desaturase 1 gene $(S C D)$ located on BTA 26 to affect curd firmness when studying Brown Swiss. This suggests that also other genomic regions may be of importance and might be found in a larger sample population.

\section{Major QTL in Relation to the Casein Cluster}

The most promising region was identified on BTA 6 . This major QTL was identified around the CN cluster for all traits analyzed. The genome-wide significant result of the haplotype analysis of the different traits estimated the additive genetic effects to be high, and the phenotypic variance explained was identified to be between 5.7 and 14.0\%. Because different SNP sets were identified within the QTL region for the different traits, the haplotypes did not include the same SNP even though they overlapped. In 3 cases, RCT, $\mathrm{G}_{30}^{\prime}$, and $\mathrm{G}_{\text {max }}^{\prime}$, the most significant $\mathrm{SNP}$ identified was found about $11 \mathrm{~kb}$ upstream CSN1S2 coding for $\alpha_{\mathrm{S}_{2}} \mathrm{CN}$. However, SNP surrounding all the other CN genes were also identified to be significant. For RCT, the effect of having the significant haplotype would introduce an increase in time before onset of gelation, which is not beneficial. Fortunately, only $27.6 \%$ of the animals carry this haplotype. The fixed effect of the most common haplotype regarding $\mathrm{G}_{30}^{\prime}$ and $\mathrm{G}_{\max }^{\prime}$ is beneficial as the cow population would gain improved milk gelation properties from having this haplotype at a higher frequency. As the frequencies of the haplotypes in the population were identified to be relatively low, 27.3 and $44.5 \%$, respectively, it would be possible to increase the frequencies in the population.

The effect of $\alpha_{\mathrm{S}_{2}} \mathrm{CN}$ on rennet-induced gelation, both regarding posttranslational modifications and concentration, is scarcely investigated. Sodeland et al. (2011) identified SNP in the promoter and 5'-flanking untranslated region of the gene coding for $\alpha_{\mathrm{S}^{2}} \mathrm{CN}$ that might have an effect on total protein yield. Results shown in a study from Bonfatti et al. (2010) indicate that the concentration of $\alpha_{S_{2}-} \mathrm{CN}$ could have a small positive effect on RCT and $\mathrm{G}^{\prime}$. Furthermore, Jensen et al. (2012) found that the relative concentration of $\alpha_{\mathrm{S}_{2}} \mathrm{CN}$ was higher in poorly coagulating milk than in well-coagulating milk. However, in that study, the effect was only significant for the Jersey breed and not the Holstein breed. Regarding posttranslational modifications, $\alpha_{\mathrm{S}^{2}} \mathrm{CN}$ is present in many different phosphorylated forms, and Frederiksen et al. (2011a) found a higher proportion of the more phosphorylated forms in the milk with the poorer gelation properties. The QTL region on chromosome 13 having a negative effect on RCT included the gene for one of the $\mathrm{CN}$ kinases (CSNK2A1). Casein kinases are located in the mammary gland, where they are involved in the phosphorylation of the CN (West and Clegg, 1984). Hence, it is possible that the expression as well as the degree of phosphorylation of $\alpha_{S_{2}}$ - $\mathrm{CN}$ is related to the gelation properties.

For YS, the peak was located more distally on chromosome 6 . The most frequent haplotype had a frequency within the population of $34.9 \%$ and introduces a loss in YS compared with the other haplotypes. Because the noncoagulating samples were not included in the YS trait, this might be the reason for the QTL peaking in a different region compared with the other rheological traits analyzed. The 2 most significant SNP were located in the second intron and upstream the CSN3 gene coding for $\kappa-\mathrm{CN}$, respectively. In contrast to $\alpha_{\mathrm{S}_{2}} \mathrm{CN}$, extensive research has been conducted regarding the effect of $\kappa-\mathrm{CN}$ on rennet-induced gelation. The effect of $\kappa$-CN has been shown to be related to the different genetic variants, as previously reviewed (Caroli et al., 2009; Bittante et al., 2012). Hallén et al. (2007) found that the genetic variant $\kappa-\mathrm{CN} B$ has a positive effect on rennet-induced gelation. Bonfatti et al. (2010) found that higher relative concentrations of $\kappa$-CN has a favorable effect on gelation time and $\mathrm{G}^{\prime}$, which is strengthened by the findings of Hallén et al. (2008), who found that $\kappa-\mathrm{CN} \mathrm{B}$ is associated with higher proportions of $\kappa$ - $\mathrm{CN}$ to total protein concentration. Furthermore, Jensen et al. (2012) found that the relative concentration of $\kappa-\mathrm{CN}$ is lower in poorly and noncoagulating milk than in well-coagulating milk but also that there is a lower fraction of glycosylated forms of $\kappa-\mathrm{CN}$. This is supported by Robitaille et al. (1993), who found that the degree of glycosylation of $\kappa-\mathrm{CN}$ has a positive effect on rennet-induced gelation. Interestingly, a significant region identified in the present study contains the GALNT1 gene coding for GalNAc-T located on BTA 24. The region on BTA 24 was identified to affect $\mathrm{G}_{30}^{\prime}$, and the significant haplotype within the region is estimated to explain about $6.9 \%$ of the phenotypic variance of the trait. It is known that the UDPGalNAc:polypeptide $N$-acetylgalactosaminyltransferase (GalNAc-T) enzymes play a role in the glycosylation of к-CN (Holland et al., 2005), and Lemay et al. (2009) place the GALNT1 gene in the mammary gland gene set. Furthermore, the study by Tyrisevä et al. (2008) likewise identified a significant locus affecting rennetinduced gelation on BTA 24, and because of the wide 
confidence intervals in their study, it could potentially represent the same region. In addition, a locus affecting $\mathrm{pH}$ within the same region was also identified.

Even though a higher degree of glycosylation of $\kappa$-CN has been shown to positively affect rennet-induced gelation (Robitaille et al., 1993; Jensen et al., 2012; Bonfatti et al., 2014), this is not straightforward to explain because the part of $\kappa$-CN (the caseinomacropeptide or, in case of glycosylation, the glycomacropeptide) harboring the glycosylation sites is cleaved off by chymosin before gelation. One possible explanation could be that the negatively charged, glycosylated peptide, the glycomacropeptide, dissociates faster from the micellar surface than the unglycosylated caseinomacropeptide, due to its higher solubility, and thereby promotes aggregation of the micelles and initiation of gelation. Robitaille et al. (1993) argue that different levels of glycosylation could lead to differences in CN micelle size, which could explain the effect of glycosylation on gel properties. Furthermore, Frederiksen et al. (2011a) and Gustavsson et al. (2014b) found that milk with smaller CN micelles has shorter gelation times and forms firmer gels than milk with larger $\mathrm{CN}$ micelles. As discussed earlier, both the significant QTL on BTA 13 and the QTL on BTA 27 harbor SNP that has been associated with relative (Schopen et al., 2011) and absolute concentration (Gambra et al., 2013) of $\kappa-\mathrm{CN}$. This shows that $\kappa-\mathrm{CN}$ is a good marker for rennet-induced gelation and shows that the effects cannot be explained by the CSN3 gene itself.

\section{Proteolysis of the Caseins}

The QTL identified on BTA 13 has a large significant effect on RCT. Interestingly, this QTL is located near the CTSZ gene coding for cathepsin Z (also called cathepsin $\mathrm{X}$ or $\mathrm{P}$ ), a lysosomal cysteine protease (Rawlings et al., 2012). It has been shown that another lysosomal cathepsin, the aspartic proteinase, cathepsin $\mathrm{D}$, is present in milk, either in its active form or proform (Larsen and Petersen, 1995). This protein plays a role in the proteolysis of $\mathrm{CN}$ in milk, not only by cleaving especially $\alpha_{S_{1}}$ CN, but it can also cleave $\kappa-\mathrm{CN}$ and release caseinomacropeptide or glycomacropeptide in resemblance with chymosin (Larsen et al., 1996). Information on proteolytic activity of cathepsin $\mathrm{Z}$ on milk proteins is lacking; however, it is known that cathepsin $\mathrm{Z}$ has some similarities with cathepsin B, which has been shown to be present in milk (Magboul et al., 2001), both being cysteine proteases with carboxypeptidase activities, though cathepsin $\mathrm{B}$ has also endoproteinase activity (Barrett et al., 1988). Cathep$\sin \mathrm{B}$ is also able to cleave the $\mathrm{CN}$ but is known to be less specific than cathepsin $\mathrm{D}$ in its proteolytic activity on $\alpha_{\mathrm{S}^{-}}$and $\beta-\mathrm{CN}$ (Larsen et al., 1996). Furthermore, within the QTL on BTA 29 identified to affect both YS and $\mathrm{G}_{30}^{\prime}$, the cathepsin $\mathrm{C}$ gene $(C T S C)$ was identified as a possible candidate gene. Wickramasinghe et al. (2012) found that both the CTSZ and CTSC genes are highly expressed in somatic cells together with $C T S B$ and CTSD, and it is well established that the breakdown of CN in milk increases with an increasing SCC because of the enzymatic activity of different proteases (Larsen et al., 2006). The haplotype on BTA 13 gives a shorter RCT and the haplotypes on BTA29 have a significant positive effect on $\mathrm{G}^{\prime}{ }_{30}$ and YS, indicating a potential positive influence of certain indigenous milk proteases on the rennet-induced milk gelation process (Larsen et al., 1996). The SCC of the milk samples in the present study ranged from 2,000 to 278,000 cells/ $\mathrm{mL}$, with an average of 47,000 cells $/ \mathrm{mL}$. No association between the traits analyzed and SCC was identified in the present study. Whether these 2 cathepsins are, in fact, the responsible loci needs to be confirmed by additional analysis.

\section{CONCLUSIONS}

To our knowledge, this is the first study identifying genomic regions affecting rennet-induced gelation of skim milk through a high-density GWAS. Of the 21 genomic regions identified, 4 were shown to affect more than one trait. The most significant genomic region affected all traits and harbors the $\mathrm{CN}$ cluster, which has also been identified in previous studies to play an important role in rennet-induced gelation. In this study the CSN1S2 and CSN3 genes were identified to be important. In addition, other regions were found to harbor potential candidate genes. The $\mathrm{G}^{\prime}$ might possibly be influenced by O-glycosylation of $\kappa-\mathrm{CN}$ (GALNT1). Furthermore, 2 potential candidate genes $(C T S Z$ and $C T S C)$ were identified within QTL regions. These cathepsins may have a proteolytic effect on $\mathrm{CN}$. Both cathepsin genes have been found to be expressed in somatic cells present in bovine milk. Our analysis shows that even though a large proportion of the phenotypic variance can be explained from haplotypes identified around the $\mathrm{CN}$ gene cluster, rennet-induced gelation properties are affected by other genes as well. This might explain some of the inconsistencies identified when only looking at the genetic variants of the $\mathrm{CN}$ genes. However, further analysis is needed for confirmation.

\section{ACKNOWLEDGMENTS}

The authors thank the Swedish Farmer's Foundation for Agricultural Research (SLF), Stockholm, Sweden, for financial support through the project "Milk genom- 
ics - Genetic influence on milk composition and technological properties in Swedish and Danish milk," which is part of the Danish-Swedish Milk Genomics Initiative. Furthermore, the authors thank Arla Foods amba, the Danish Strategic Research Council, the Danish Cattle Federation, and Aarhus University for financial support through the project "Impact of genes on variations in milk composition and quality," also part of the DanishSwedish Milk Genomics Initiative. Finally, we thank Henriette Pasgaard Bertelsen for precipitation of the blood samples, and the rest of the Danish sampling and analysis team of the Milk Genomics Initiative is gratefully acknowledged for excellent technical assistance.

\section{REFERENCES}

Barrett, A. J., D. J. Buttle, and R. W. Mason. 1988. Lysosomal cysteine proteinases. Pages 256-260 in ISI Atlas of Science: Biochemistry. Cambridge University Press, Cambridge, UK.

Barrett, J. C., B. Fry, J. Maller, and M. J. Daly. 2005. Haploview: Analysis and visualization of LD and haplotype maps. Bioinformatics 21:263-265.

Bates, D. M., M. Maechler, and B. Dai. 2008. Ime4: Linear mixedeffects models using S4 classes. R package version 0.999375-28. Accessed Dec. 2, 2014. http://lme4.r-forge.r-project.org/.

Bittante, G., M. Penasa, and A. Cecchinato. 2012. Invited review: Genetics and modeling of milk coagulation properties. J. Dairy Sci. 95:6843-6870.

Bonfatti, V., G. Chiarot, and P. Carnier. 2014. Glycosylation of k-casein: Genetic and nongenetic variation and effects on rennet coagulation properties of milk. J. Dairy Sci. 97:1961-1969.

Bonfatti, V., G. Di Martino, A. Cecchinato, L. Degano, and P. Carnier. 2010. Effects of $\beta$ - $\kappa$-casein (CSN2-CSN3) haplotypes, $\beta$-lactoglobulin (BLG) genotypes, and detailed protein composition on coagulation properties of individual milk of Simmental cows. J. Dairy Sci. 93:3809-3817.

Caroli, A. M., S. Chessa, and G. J. Erhardt. 2009. Invited review: Milk protein polymorphisms in cattle: Effect on animal breeding and human nutrition. J. Dairy Sci. 92:5335-5352.

Cecchinato, A., and P. Carnier. 2011. Short communication: Statistical models for the analysis of coagulation traits using coagulating and noncoagulating milk information. J. Dairy Sci. 94:4214-4219.

Cecchinato, A., M. Penasa, M. De Marchi, L. Gallo, G. Bittante, and P. Carnier. 2011. Genetic parameters of coagulation properties, milk yield, quality, and acidity estimated using coagulating and noncoagulating milk information in Brown Swiss and HolsteinFriesian cows. J. Dairy Sci. 94:4205-4213.

Cecchinato, A., C. Ribeca, A. Maurmayr, M. Penasa, M. De Marchi, N. P. P. Macciotta, M. Mele, P. Secchiari, G. Pagnacco, and G. Bittante. 2012. Short communication: Effects of B-lactoglobulin, stearoyl-coenzyme A desaturase 1 , and sterol regulatory element binding protein gene allelic variants on milk production, composition, acidity, and coagulation properties of Brown Swiss cows. J. Dairy Sci. 95:450-454.

de Bakker, P. I., N. P. Burtt, R. R. Graham, C. Guiducci, R. Yelensky, J. A. Drake, T. Bersaglieri, K. L. Penney, J. Butler, S. Young, R. C. Onofrio, H. N. Lyon, D. O. Stram, C. A. Haiman, M. L. Freedman, X. Zhu, R. Cooper, L. Groop, L. N. Kolonel, B. E. Henderson, M. J. Daly, J. N. Hirschhorn, and D. Altshuler. 2006. Transferability of tag SNPs in genetic association studies in multiple populations. Nat. Genet. 38:1298-1303.

Farrell, H. M., R. Jimenez-Flores, G. T. Bleck, E. M. Brown, J. E. Butler, L. K. Creamer, C. L. Hicks, C. M. Hollar, K. F. Ng-KwaiHang, and H. E. Swaisgood. 2004. Nomenclature of the proteins of cows' milk—Sixth revision. J. Dairy Sci. 87:1641-1674.
Frederiksen, P. D., K. K. Andersen, M. Hammersh $\varnothing$, H. D. Poulsen, J. Sørensen, M. Bakman, K. B. Qvist, and L. B. Larsen. 2011a. Composition and effect of blending of noncoagulating, poorly coagulating, and well-coagulating bovine milk from individual Danish Holstein cows. J. Dairy Sci. 94:4787-4799.

Frederiksen, P. D., M. Hammershøj, M. Bakman, P. N. Andersen, J. B. Andersen, K. B. Qvist, and L. B. Larsen. 2011b. Variations in coagulation properties of cheese milk from three Danish dairy breeds as determined by a new free oscillation rheometry-based method. Dairy Sci. Technol. 91:309-321.

Gambra, R., F. Penagaricano, J. Kropp, K. Khateeb, K. A. Weigel, J. Lucey, and H. Khatib. 2013. Genomic architecture of bovine kappa-casein and beta-lactoglobulin. J. Dairy Sci. 96:5333-5343.

Glantz, M., H. Lindmark Månsson, H. Stålhammar, and M. Paulsson. 2012. Effect of polymorphisms in the leptin, leptin receptor and acyl-CoA:diacylglycerol acyltransferase 1 (DGAT1) genes and genetic polymorphism of milk proteins on bovine milk composition. J. Dairy Res. 79:110-118.

Glantz, M., H. Lindmark Månsson, H. Stålhammar, and M. Paulsson. 2011. Effect of polymorphisms in the leptin, leptin receptor, and acyl-coenzyme A:diacylglycerol acyltransferase 1 (DGAT1) genes and genetic polymorphism of milk proteins on cheese characteristics. J. Dairy Sci. 94:3295-3304

Gregersen, V. R., L. N. Conley, K. K. Sørensen, B. Guldbrandtsen, I. H. Velander, and C. Bendixen. 2012. Genome-wide association scan and phased haplotype construction for quantitative trait loci affecting boar taint in three pig breeds. BMC Genomics 13:22.

Gustavsson, F., A. J. Buitenhuis, M. Glantz, H. Stålhammar, H. Lindmark-Månsson, N. A. Poulsen, L. B. Larsen, A. Andrén, and M. Paulsson. 2014a. Impact of genetic variants of milk proteins on chymosin-induced gelation properties of milk from individual cows of Swedish Red dairy cattle. Int. Dairy J. 39:102-107.

Gustavsson, F., M. Glantz, A. J. Buitenhuis, H. Lindmark-Månsson, H. Stålhammar, A. Andrén, and M. Paulsson. 2014b. Factors influencing rennet-induced gelation of milk from individual dairy cows: Major effects of casein micelle size and calcium. Int. Dairy J. 39:201-208.

Gustavsson, F., M. Glantz, N. A. Poulsen, L. Wadsö, H. Stålhammar, A. Andrén, H. Lindmark Månsson, L. B. Larsen, M. Paulsson, and W. F. Fikse. 2014c. Genetic parameters for rennet- and acidinduced coagulation properties in milk from Swedish Red dairy cows. J. Dairy Sci. 97:5219-5229.

Hallén, E., T. Allmere, J. Näslund, A. Andrén, and A. Lundén. 2007. Effect of genetic polymorphism of milk proteins on rheology of chymosin-induced milk gels. Int. Dairy J. 17:791-799.

Hallén, E., A. Wedholm, A. Andrén, and A. Lundén. 2008. Effect of beta-casein, kappa-casein and beta-lactoglobulin genotypes on concentration of milk protein variants. J. Anim. Breed. Genet. 125:119-129.

Holland, J. W., H. C. Deeth, and P. F. Alewood. 2005. Analysis of O-glycosylation site occupancy in bovine kappa-casein glycoforms separated by two-dimensional gel electrophoresis. Proteomics 5:990-1002.

Holland, S. M. 2008. Principal Components Analysis (PCA). University of Georgia, Athens.

Ikonen, T., K. Ahlfors, R. Kempe, M. Ojala, and O. Ruottinen. 1999. Genetic parameters for the milk coagulation properties and prevalence of noncoagulating milk in Finnish dairy cows. J. Dairy Sci. $82: 205-214$

International Dairy Federation. 2013. The World Dairy Situation 2013. Bulletin 470/2013. International Dairy Federation, Brussels, Belgium.

Jensen, H. B., N. A. Poulsen, K. K. Andersen, M. Hammershøj, H. D. Poulsen, and L. B. Larsen. 2012. Distinct composition of bovine milk from Jersey and Holstein-Friesian cows with good, poor, or noncoagulation properties as reflected in protein genetic variants and isoforms. J. Dairy Sci. 95:6905-6917.

Kolbehdari, D., Z. Wang, J. R. Grant, B. Murdoch, A. Prasad, Z. Xiu, E. Marques, P. Stothard, and S. S. Moore. 2009. A whole genome scan to map QTL for milk production traits and somatic cell score in Canadian Holstein bulls. J. Anim. Breed. Genet. 126:216-227. 
Larsen, L. B., C. Benfeldt, L. K. Rasmussen, and T. E. Petersen. 1996 Bovine milk procathepsin D and cathepsin D: Coagulation and milk protein degradation. J. Dairy Res. 63:119-130.

Larsen, L. B., P. L. H. McSweeney, M. G. Hayes, J. B. Andersen, K. L. Ingvartsen, and A. L. Kelly. 2006. Variation in activity and heterogeneity of bovine milk proteases with stage of lactation and somatic cell count. Int. Dairy J. 16:1-8.

Larsen, L. B., and T. E. Petersen. 1995. Identification of five molecular forms of cathepsin D in bovine milk. Pages 279-283 in Aspartic Proteinases: Structure, Function, Biology and Biomedical Implications. K. Takahashi, ed. Springer US, New York, NY.

Lemay, D. G., D. J. Lynn, W. F. Martin, M. C. Neville, T. M. Casey, G. Rincon, E. V. Kriventseva, W. C. Barris, A. S. Hinrichs, A J. Molenaar, K. S. Pollard, N. J. Maqbool, K. Singh, R. Murney, E. M. Zdobnov, R. L. Tellam, J. F. Medrano, J. B. German, and M. Rijnkels. 2009. The bovine lactation genome: Insights into the evolution of mammalian milk. Genome Biol. 10:R43.

Lodes, A., J. Buchberger, I. Krause, J. Aumann, and H. Klostermeyer. 1996. The influence of genetic variants of milk proteins on the compositional and technological properties of milk. 2. Rennet coagulation time and firmness of the rennet curd. Milchwissenschaft 51:543-548.

Magboul, A. A. A., L. B. Larsen, P. L. H. McSweeney, and A. L. Kelly. 2001. Cysteine protease activity in bovine milk. Int. Dairy J. $11: 865-872$.

Poulsen, N. A., H. P. Bertelsen, H. B. Jensen, F. Gustavsson, M. Glantz, H. Lindmark Månsson, A. Andrén, M. Paulsson, C. Bendixen, A. J. Buitenhuis, and L. B. Larsen. 2013. The occurrence of noncoagulating milk and the association of bovine milk coagulation properties with genetic variants of the caseins in 3 Scandinavian dairy breeds. J. Dairy Sci. 96:4830-4842.

QTDT. 2005. QTDT-Download binaries (updated Aug. 2008), version 2.5.1. Accessed Feb. 27, 2014. http://www.sph.umich.edu/ csg/abecasis/QTDT/download/.

QTDT. 2008. QTDT-Association models. Accessed Feb. 27, 2014. http://www.sph.umich.edu/csg/abecasis/QTDT/docs/model.html.

Rawlings, N. D., A. J. Barrett, and A. Bateman. 2012. MEROPS: The database of proteolytic enzymes, their substrates and inhibitors. Nucleic Acids Res. 40:D343-D350.

Robitaille, G., K. F. Ng-Kwai-Hang, and H. G. Monardes. 1993. Effect of kappa-casein glycosylation on cheese yielding capacity and coagulating properties of milk. Food Res. Int. 26:365-369.

Schopen, G. C., M. H. Visker, P. D. Koks, E. Mullaart, J. A. van Arendonk, and H. Bovenhuis. 2011. Whole-genome association study for milk protein composition in dairy cattle. J. Dairy Sci. 94:3148-3158.

Sodeland, M., H. Grove, M. Kent, S. Taylor, M. Svendsen, B. J. Hayes, and S. Lien. 2011. Molecular characterization of a long range haplotype affecting protein yield and mastitis susceptibility in Norwegian Red cattle. BMC Genet. 12:70.

Sørensen, L. K., M. Lund, and B. Juul. 2003. Accuracy of Fourier transform infrared spectrometry in determination of casein in dairy cows' milk. J. Dairy Res. 70:445-452.

Swedish Dairy Association. 2011. Husdjursstatistik/Cattle Statistics 2011. Swedish Dairy Association, Stockholm, Sweden.

Tyrisevä, A. M., K. Elo, A. Kuusipuro, V. Vilva, I. Janonen, H. Karjalainen, T. Ikonen, and M. Ojala. 2008. Chromosomal regions underlying noncoagulation of milk in Finnish Ayrshire cows. Genetics 180:1211-1220.

Veerkamp, R. F., H. A. Mulder, R. Thompson, and M. P. Calus. 2011. Genomic and pedigree based genetic parameters for scarcely recorded traits when some animals are genotyped. J. Dairy Sci. 94:4189-4197.

Walstra, P. J. T. M. Wouters, and T. J. Geurts. 2006. Dairy Science and Technology. 2nd ed. Taylor and Francis, Boca Raton, FL.

Wedholm, A., E. Hallén, L. B. Larsen, H. Lindmark Månsson, A. H Karlsson, and T. Allmere. 2006a. Comparison of milk protein composition in a Swedish and a Danish dairy herd using reversed phase HPLC. Acta Agric. Scand. Anim. Sci. 56:8-15.

West, D. W., and R. A. Clegg. 1984. Casein kinase activity in rat mammary gland Golgi vesicles. Demonstration of latency and requirement for a transmembrane ATP carrier. Biochem. J. 219:181-187.

Wickramasinghe, S., G. Rincon, A. Islas-Trejo, and J. F. Medrano. 2012. Transcriptional profiling of bovine milk using RNA sequencing. BMC Genomics 13:45.

Wigginton, J. E., D. J. Cutler, and G. R. Abecasis. 2005. A note on exact tests of Hardy-Weinberg equilibrium. Am. J. Hum. Genet. 76:887-893.

Zimin, A. V., A. L. Delcher, L. Florea, D. R. Kelley, M. C. Schatz, D. Puiu, F. Hanrahan, G. Pertea, C. P. Van Tassell, T. S. Sonstegard, G. Marcais, M. Roberts, P. Subramanian, J. A. Yorke, and S. L. Salzberg. 2009. A whole-genome assembly of the domestic cow, Bos taurus. Genome Biol. 10:R42.

Zoon, P., T. van Vliet, and P. Walstra. 1989. Rheological properties of rennet-induced skim milk gels. 4. The effect of $\mathrm{pH}$ and $\mathrm{NaCl}$. Neth. Milk Dairy J. 43:17-34. 